\title{
Centralized System of Universities Learning Materials
}

\author{
Ruslan Vynokurov*, Volodymyr Tigariev, Oleksii Lopakov, Kateryna Kirkopulo, Olena Pavlyshko \\ Odessa National Polytechnic University, Institute of Industrial Technologies Design and Management, 65044, Ukraine
}

\begin{tabular}{l} 
A R T I C L E I N F O \\
\hline Article history: \\
Received: 15 January, 2020 \\
Accepted: 11 April, 2020 \\
Online: 03 May, 2020 \\
\hline
\end{tabular}

Keywords:

Distance Learning

Education

Studying

Website

$V R$

$A R$

\begin{abstract}
A B S T R A C T
This article considers the creation of a program / website as an example of a centralized system for all universities in order to more easily familiarize an applicant and / or student with the internal politics and capabilities of the university. Existing problems in the training system are examined, why distance learning is relevant, what problems exist in it and how they can be solved. Based on the proposed distance learning projects, an argument is built on its meaninglessness without further advancement, and how a website concept can help solve this problem. The concept of the website and its possible implementation using existing analogues in other areas that successfully complete the tasks are considered. Theoretically, using the proposed methods, the concept will simplify the choice of a further place of study for schoolchildren and applicants. The method consists in parsing the desired university website into the necessary categories: a number of specialties, disciplines, foreign programs, distance learning materials and so on. This will allow you to create a library of universities, their materials and open data (specialties, disciplines), without coming to excesses, such as creating a video hosting service for broadcasting recorded disciplines, less data to be stored, and more.
\end{abstract}

\section{Introduction}

This paper is an extension of work originally presented in IEEE PICS\&T 2018 [1].

The purpose of this article is to consider the possibility of creating a website that will combine higher education institutions with the goal of easier navigation in higher education.

The original article examined why the decision to use the Unreal Engine 4 (https://www.unrealengine.com/en-US/) game engine is relevant to create a platform. Thanks to blueprint technology, which is a system of nodes with built-in code scripts, you can easily perform many tasks without knowing the syntax of a programming language, in this case $\mathrm{C}++$. Saving time for studying the syntax and focusing forces on the program logic, it becomes possible to devote more time directly to the program itself, which positively affects the quality.

Also in the original article, the creation of a workflow for filling the platform with materials was considered: what components are needed to create a working system, what programs and their bounds were proposed for compiling the content of the proposed lessons, a conceptual example used at the Odessa

*Ruslan Vynokurov, Email: ruslan.vinokurov14@gmail.com
National Polytechnic University was considered. All this was done in order to describe one of the possible options for creating such a platform/hub, where students could find the materials they need and navigate the relevance of knowledge that the university has been presenting during the studying.

This article focuses on the consideration of the previously described problem, its expansion and argumentation. An approach was taken to collect information from third-party sources and combine them to provide more specific structured information to applicants through the website. The process of the platform creation was partially considered $[1,2]$.

At the moment, students are often not aware of what universities are like. According to the experience of the authors who live in Ukraine, at the start of student enrollment, different universities arrange open house days when you can go in and look at the place where the applicant thinks to continue his studies. According to this event, the student receives a plot of information about who he will study with, who will teach him and what he will be able to achieve. Often, since in Ukrainian universities a shortage of students in certain specialties is a frequent occurrence, it is customary to embellish a university story and indicate only the advantages of the specialty and/or specialization, without informing applicants about possible shortcomings. The 


\section{R. Vynokurov et al. / Advances in Science, Technology and Engineering Systems Journal Vol. 5, No. 3, 28-33 (2020)}

disadvantages can be in different areas: poor teaching staff, the relevance of the teaching materials presented, poor learning conditions and more.

There is also the problem of choice, which should solve the confines between graduation and the beginning of a university.

The problems that prevent students from choosing their future profession will be considered below.

\section{Main Problem}

There are a number of problems that do not allow obtaining the necessary knowledge for a person. It is also necessary to indicate that these problems are considered in several areas: preparation of the applicant for admission to the university and student gaining knowledge in the university environment. According to the authors, there are two most common problems:

- The problem of awareness.

- The problem of the existing education system.

\subsection{Awareness problem}

The authors' experience is based on a model of the Bologna system, as well as on the basis of statistics from some universities in the Russian Federation. The moment of transition from school to a higher educational institution often raises many questions, since this stage is constantly updated and supplemented by various acts. All these updates are briefly explained, but the busyness of schoolchildren with the upcoming exams does not make it possible to immerse themselves in the question completely.

The exam procedure itself is relatively simple, but preparing for them can entail enormous costs in time, which limits students in reflecting on who they want to become in the future. Short time for studying the material and pressure from the family and the teaching staff leads to procrastination among schoolchildren, which affects their general level of anxiety, productivity and academic performance [3]. Such employment and a psychologically difficult situation do not allow the student to adequately assess their strengths and weaknesses, which would allow to come to the correct decision regarding the choice of specialty and specialization.

According to the considered statistics, only $11 \%$ of schoolchildren in grades 8-9 are determined with the place of forthcoming education. $54.1 \%$ is determined only by the end of grade $11.5 .2 \%$ of students initially knew where they would go. $19.7 \%$ are determined either immediately before admission, or do not do it at all. The choice is complicated by a large number of criteria and a variety of conditions, thanks to through which the choice of university is made: parents' advice, teachers' advice, print university advertising, television and radio advertising, open day at the university, conversations with university students, speeches, meetings, conversations with teachers, job fairs, university rankings in the media and more [4]. Due to the fact that applicants cannot decide on the choice of a profession at school, they are trying to find the specialty that is relevant and necessary at the time of selection - the trend.

Often, professions are selected on the basis of superficial knowledge about this type of activity. Each specialty has its own requirements for a person in different fields: level of knowledge, stress tolerance, responsibility, level of emotional intelligence, sociability, teamwork and other human qualities. This can be called a characteristic of a single profession, which for the most part should be observed in candidates. Many people make an unconscious choice of their future profession, since the characteristic is a huge amount of details and, often, the only way to understand whether you can relate to this specialty is an internship, which can be completed with an average level of knowledge in the specialty, which suggests studying in this area. Therefore, those $54.1 \%$, as well as $19.7 \%$ of schoolchildren who make decisions at the last moment, cannot have a complete picture of what they need to study in order to become a specialist in a certain kind of activity, since this requires a lot of amount of time. This leads to poor-quality training of students due to the lack of their motivation to study further. And this, in turn, to work not in the specialty and lack of qualifications in another kind of activity.

\subsection{Education system problem}

Countries should try to develop in the field of education as fast as countries with similar capabilities do [5]. The main problem in the development of distance learning is an incorrect education system. According to statistics from the American Federation's National Policy Summit for Children, online schools in their early days did not achieve proper exams due to funding for a nonworking education system. From the very beginning, virtual schools were suitable only for some disciplines [6], but with the advent of new mechanics it became stronger in others, which gradually leads to the popularity of this approach for learning.

In the CIS countries, this situation lies in the lag of the teaching methodology, which is manifested in the students' lack of interest, since the training system is not clear and complex, which leads to a lack of understanding of the need for a particular discipline and/or specialty as a whole. This is due to the formalism of the materials presented. It is expressed in a mechanical, passive, insufficiently meaningful assimilation by students of teaching material, in memorizing verbal formulas by them, devoid of specific content, in the inability to connect the knowledge gained with life [7]. This educational system was used in the USSR and developed to the maximum possible to meet the requirements of the ruling party. Subsequently, the education system was not changed and only updated the knowledge provided, which led to the depletion of the system and its inability to improve further, namely, to include modern technologies as part of the learning process, such as AR/VR/MR and so on [8].

\section{Information About Distance Learning}

At the moment, distance learning is becoming more and more popular in the world, which helps many students to gain knowledge without being in an educational institution. Distance learning is gradually becoming the standard throughout the world. This can be seen by the number of queries in popular search engines. For example, according to the data from the multifunctional SEO platform Serpstat, on google.com the query "distance learning" is entered into the search line 133900 times a month (on average for 2019), and the phrase "online school" is 255300 times under the same conditions. Now the term "online school" is becoming popular, which consists in distance learning through various communication platforms and video conferencing 
of the teacher. Special business accelerators are being created, which are aimed at helping start-ups and companies related to this type of studying and helping to transform a successful business out of it through templates and promotion schemes.

The largest universities in the world have long possessed this type of education, for example: Boston, Florida and Arizona State Universities, the University of Wisconsin at Madison, as well as the State University of Pennsylvania in the USA. With the help of this system, the University of Florida allowed 400000 students to get education in 135 countries of the world. There are examples in the UK: University of Liverpool, Suffolk University Campus, Ruskin University England, School of Oriental and African Studies, University of Manchester. The latter currently provides knowledge to about 40000 students only through distance learning in 154 countries around the world [5].

\subsection{What is wrong with distance learning organization}

Despite such local and international success, it is not possible to refer to the current distance learning - there is no primary source that would immediately tell about many available options from different universities and at the same time give access and description to it.

The above examples are well-known mastodons of science, which in any case will be found by applicants if they wish, because you can hear about them at school age as the most desirable places to study, but applicants absolutely do not know anything about other places, which also may be good for learning. Examples show that distance learning is valid, but it is impossible to confine oneself only to these mastodons - on the contrary, it is necessary to expand knowledge, it is necessary to make it clear that the world of education is much wider and more spacious, and does not close to the top ten most popular universities.

For example, the YouTube website (https://www.youtube.com/) is a great place to store distance learning videos, but it was not originally created for this. You can restrict access to video, as well as collect video playlists, but adding a description to each playlist to make it convenient is impossible due to lack of functionality. And it would be possible to create an analogue of Instant View (hereinafter referred to as the IV) from Telegram (https://telegram.org/) and still store the video on a service from Google, but at the same time pre-set and display it with the necessary data on the website.

The point is that it is necessary to fundamentally change the existing system and introduce a core that can connect all that is different that exists at the moment. Each person should have the opportunity to look at different universities and decide which one will be most suitable for him. This implies the lack of centralization of the final result, in this case, the showcase of distance learning and the university as a whole.

\subsection{Why is this a problem}

At this stage, an applicant who has the opportunity to enter any university should find universities on the Internet and check the availability of specialties, specializations, what he will be taught, who he will become in the end, what perspectives the industry has and much more. It takes time to surf on the Internet, which students do not have, as it was described earlier. The problem is that the more responsible the student approaches the question of exams, the more irresponsible he is to his future. It is quite difficult to find a balance, since both questions are complex and difficult to study, so the idea of centralizing information about universities from one point seems quite reasonable.

\subsection{How a solution to this problem affects on progress}

When a website appears with an extensive list of universities, it becomes possible to compare their statistics: popular specialties, the relevance of discipline programs, teacher qualifications, etc.

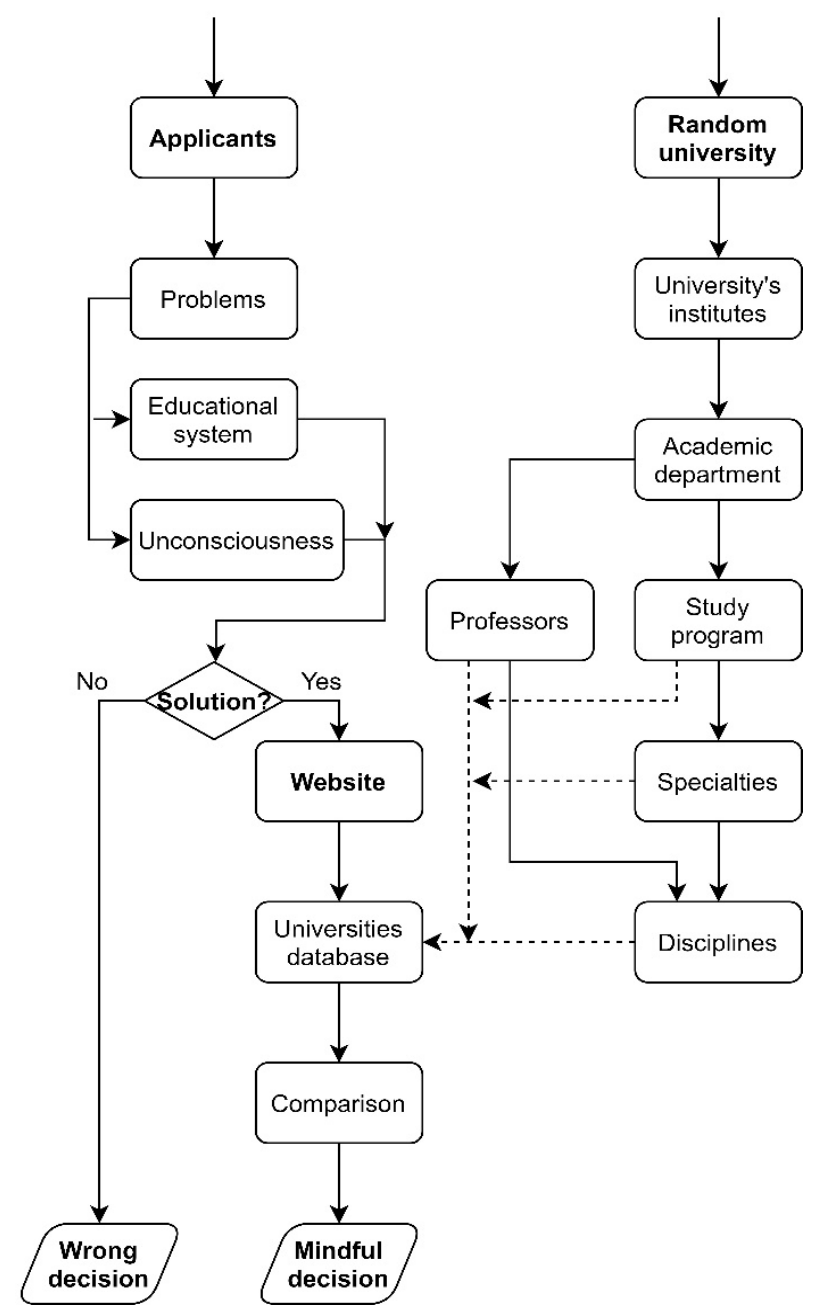

Figure 1: Scheme of each applicant choice and how the solution should be implemented.

Thanks to this website, students can easily compare and contrast universities: see different and general, study programs, with which foreign partners there is cooperation, foreign programs, opportunities for graduation, with which companies the educational institution cooperates. Also, applicants gain the opportunity to see other universities, the existence of which they might not know. Since the website will also have distance learning materials, this allows applicants to review the teaching methodology, compare with other universities and make an informed decision about admission to a particular educational institution.

This implies a great knowledge of the choice of a university, as well as a dry balance of the necessary information without frills, 


\section{R. Vynokurov et al. / Advances in Science, Technology and Engineering Systems Journal Vol. 5, No. 3, 28-33 (2020)}

which allows a sober assessment of the proposed educational institution. As a result, students study in more relevant specialties for them at the universities most suitable for this, which is what the research of this article seeks. The overall idea is described on the Figure 1.

\section{Solution}

The examples of solutions that allow you to learn much more efficiently and faster are shown below, but due to the lack of information about such solutions, few people think about their existence. At the same time, they can provide an incentive to create competitive software, or make additions to existing code, which will improve the UX and functionality of existing programs. This approach is widespread in the IT field and this is evidenced by such communities as GitHub, Stack overflow, the open source Unreal Engine 4, which can be supplemented by various plug-ins and the Blender 3D modeling program, which also has open source code and can be supplemented by functionality that users deem necessary.

All this speaks of the popularity of the approach when people, specialists in their field, are aware of this. That is why it is necessary to show and disseminate new techniques and show them to a wide audience, in which the proposed website concept can help.

\subsection{Solution examples}

There are different AR applications and many of them have very different goals. AR technology allows you to reproduce objects that are difficult to read in $3 \mathrm{D}$ models, which makes it easier to accept abstract and complex content. This is useful for those who remember visually and who need a translation of the theory into a tangible concept. For example, Polytechnic University of Leiria, in Portugal introduced AR to math classes and students speak of it as a very useful, easy and interesting solution.

Nvidia Holodeck may be an example of VR technology, whose technology allows people from different parts of the planet to work together in virtual space, makes it possible to develop design, assembly lines, technological processes and much more, having their 3D counterparts in a virtual environment [1].

A team from Stanford University created a project called STRIVR. It began as a VR training tool for their university football team. Subsequently, they found out about the project, and it turned into a platform for staff training and works with companies such as Walmart. United Rentals (hereinafter referred to as UR), which is the largest equipment rental company in North America, trains third-party sales representatives (hereinafter referred to as TPSR) using STRIVR technology. Using photos or videos in the classroom does not allow students to gain practical experience, because UR used the STRIVR immersion platform to create the next generation TPSR tutorial that uses VR technology. It includes 5 practical steps in VR, so that training takes place with a sense of presence directly at the workplace, but actually not there. Thus, they achieved an increase in efficiency and reduced training time by $40 \%$ [1].

\subsection{Conclusions from the proposed concepts}

Above are local, point solutions that allow you to gain an increase in the effectiveness of training using practical experience.
This decision is relevant, as the current education system in the CIS has reached its maximum. At the moment, it cannot fully compare the modern requirements of social expectations and real educational results [8], which leads to a lag and less interest of students to study.

Also, these examples are relevant, since AR/VR/MR technologies are considered one of the most promising technologies of the 21 st century, and also create new ways of presenting information and studying.

The disadvantage of this system is the lack of cooperation between such solutions, which does not allow to switch from one technology to another within the framework of one application. Having created a common basis that opens up access to any of these solutions, you can think about implementing a technology that will demonstrate different disciplines (where applicable), allowing students to understand what a single discipline is in a particular specialty and what it is manifests itself.

This technology allows to solve the problem of awareness in view of a more affordable solution for students and the opportunity to get some practical experience immediately before studying in this area.

Also, this system involves either a complete change in training programs, or their adaptation to a new approach, which solves the problem of the education system and allows to increase the effectiveness of training, a more relevant choice by students of future specialties and areas in which they will study.

\subsection{Suggestion of solution}

It is proposed to create a website. It will serve as the basis for comparing universities, searching for information about educational institutions, study programs in them. It is proposed to minimize the work and use what already exists, namely, materials and approaches.

Telegram messenger has IV technology, which was created specifically to display the content of other websites inside the messenger. When a user shares a website link inside Telegram, a bot instantly fires, which checks for the presence of a template for the website. A template is a set of rules that interprets a website as necessary, removing all unnecessary and leaving a purely necessary context in the form of text, links, tables, images. If such a template is found, the website opens inside the messenger without loading the page - instantly. It is noteworthy that any user can create a template and send it to the messenger developers for verification and subsequent approval. After confirming the suitability of the template, any page of the website will open according to the rules established in the template.

The idea of the proposed website is a similar approach. Instead of re-creating the content, you can duplicate it and interpret it in the right way, managing the content as you need.

This solution allows you not to create your own video hosting services, like YouTube, for storing university video data. Instead, you can simply link to existing pages and present information from the websites of universities and their individual projects, whether it's distance learning, or international programs, in one light and together in a user-friendly way. 


\section{R. Vynokurov et al. / Advances in Science, Technology and Engineering Systems Journal Vol. 5, No. 3, 28-33 (2020)}

This will allow you to view from one place all those existing lectures and materials, regardless of what they will be: an article, video, or the AR / VR / MR application. In the case of the latter, most likely, it will be necessary to install additional software recommended for their reproduction, but such a question is not included in the scope of this article.

The uniqueness and unification of the website is a guarantee of freedom in the implementation of projects (websites) of other universities. The existence of such a website will not limit the creators of university websites to change anything in the design or development approach.

\section{Implementation}

As mentioned earlier, the concept is a website that uses a similar IV technology created by Telegram.

The proposed website concept can solve the problems indicated in section 2. Since the concept collects a database of different places for higher education, having the ability to expand and modify the list of institutions and their characteristics according to the method below, the problem of awareness can be overcome with a single condition: the provision of such a basis to applicants in advance and with an explanation.

The system works like an online store with a large number of filters - what interests the applicant has selected: direction, specialty (final profession), country, tuition fees, other filters that will allow you to get a selection of final results. Provides a description of the specialty, possible previews of training materials for better reference. Applicants have a chance to look at a specialty and form an opinion about it, which makes it easier to make a decision.

The final result of solving the problem of awareness remains behind the desire of applicants to understand this issue, but the presented concept will simplify the task for them by collecting everything they need in a single database.

Initially, existing university materials will be presented, both on distance learning and lecture materials from various platforms, for example, YouTube. The website will initially focus on downloading various additional materials from external sources. This is due to the lack of servers and capacities that are required to service such networks. The website will only target educational materials from trusted sources that are either presented at the university, or distance learning materials. This is also the main difference from YouTube, Vimeo (https://vimeo.com/) and other similar services, where in addition to educational content, you can also find entertaining, which can distract the user. Thus, having the opportunity to accept materials from a variety of resources, the website acts as a place where only training materials will be collected.

\subsection{Functionality and purpose of the site}

To be able to open articles from a single resource, a template is created that transforms the data into the desired form and provides it in an IV which is a simplified form without such additional aspects as a list with other articles, website menu, advertising, and so on.
The transformation of the page of any resource is carried out in the following 4 steps:

- Determining which parts of a particular resource will be better suited to the conditions for creating the template;

- Parses the basis of the website for the main tags of HTML code to present them in accordance with the requirements of the template. In case an information element is found that does not meet the rules of the template, it is necessary to use the functions provided by Telegram that transform them into a suitable element;

- Remove all unnecessary content and provide a clean IV page for viewing using a dedicated feature;

- Check the template using 5-10 links to other articles of the same resource to make sure that all applied functions work correctly and there is no need to use others to display additional content (for example, replace one HTML tag with another, insert a paragraph tag inside text structures and so on).

According to a case study that was provided by Telegram based on an analysis of an article from medium.com, you can understand and take as a basic principle how the website content is transformed and its new look is compiled.

This approach is quite flexible and scalable. Also, the Telegram code is open and exposed on the GitHub resource, which allows you to use the acquired technologies as needed.

\section{Related Work}

At the moment, work is underway on the development of application authentication and the functionality of the hub start page, the second component of the proposed solution, which was presented in the original article [1]. To create authentication, a set of libraries is used to implement standard scenarios (hereinafter referred to as the SDK) of GameSparks (https://bit.ly/3besv6D), which allows us to develop user authorization logic in detail. The start page at the moment is a block that contains video, the main control panel and news.

For authentication, blueprint technology was used, which allowed us to create user registration and authentication. Figure 2 shows the blueprint used.

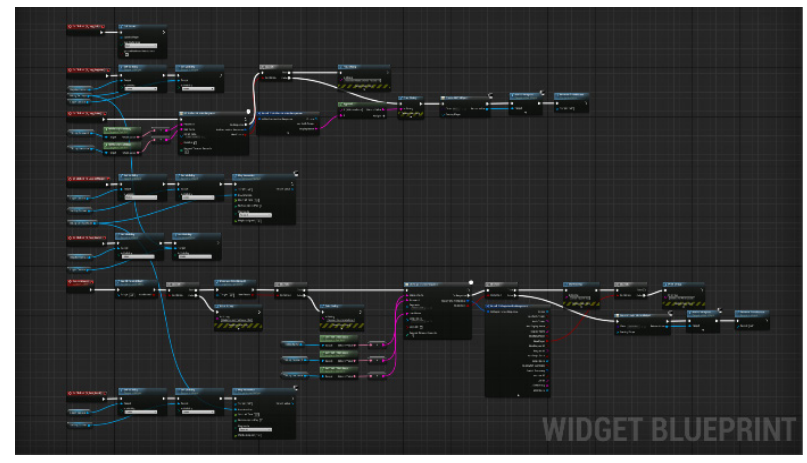

Figure 2: Authentication blueprint.

At this stage, the website has not yet been developed, since the final goal is constantly updated and optimized. 


\section{Future Work}

As the upcoming works, the authors of this article see the development of the hub application, namely the creation of an application for playing their own AR/VR/MR projects and interaction with them. It will be considered creating a user account and saving information about it inside the application, the ability to edit it. Creating basic templates for learning materials, for example: video lecture, video with auxiliary files, AR project, VR project and more, in which all the necessary variables and components that create this template will be explained and recorded. Thanks to it, content of the same type will be able to collect in arrays and automatically load.

Viewing videos from YouTube, Vimeo and similar websites will be implemented, when creating the subsequent pages of the application.

Creation of the website described in this article where the functionality for comparing universities will be created. A bundle of a website and an application for synchronizing databases, since, for example, the GameSparks SDK stores all accounts inside its server.

The application will be created using Unreal Engine 4, which will fully realize the main goal of the article: quick familiarization of applicants with the specialties and professions taught by universities in order to make a more informed and rational choice of further education.

\section{References}

[1] V. Tigariev, R. Vinokurov, A. Pavlyshko, I. Sinko, "Informational Training System Mindgate" in 2018 International Scientific-Practical Conference Problems of Infocommunications. Science and Technology (PIC S\&T), IEEE, 2019.

https://ieeexplore.ieee.org/document/8632104

[2] V. Tigariev, R. Vynokurov, "Creation Of a Learning System Based On The Game Engine Unreal Engine 4 (article in Russian with an abstract in English)" in 2018 ICT 7th International Scientific and Technical Conference, Odessa, Ukraine, 2018.

http://immm.opu.ua/files/archive/n4 v8 2018/immm n4 v8 2018.pdf

[3] J.R. Ferrari "Self-handicapping by procrastinators: Effects of task importance and performance privacy" in 1990 Doctoral dissertation, Adelphi University, Garden City, NY, USA, 1990.

[4] G. Evdonin, S. Mamedova, "Modeling of choosing of university for entrants (article in Russian with an abstract in English)" in 2014 Управленческое консультирование, 2014.

https://cyberleninka.ru/article/n/modelirovanie-protsessa-vybora-vuzaabiturientom-pri-postuplenii

[5] R. Vynokurov, "Расстояние Как Основная Проблема Информационного Обеспечения Образовательных Процессов" in 2019 TIRMIA/TI 5th International Scientific and Practical Conference of students, postgraduates and junior researches, Odessa, Ukraine, 2019.

[6] A. Molnar, G. Miron, C. Gulosino, C. Shank, C. Davidson, M. K. Barbour, L. Huerta, S. R. Shafer, J. K. Rice, D. Nitkin, "Virtual Schools in the U.S. 2017" in 2017 Boulder, CO: National Education Policy Center, 2017. https://nepc.colorado.edu/publication/virtual-schools-annual-2017

[7] O. Lebedev, "The End of Compulsory Education? (article in Russian with an abstract in English)" in 2016 Вопросы образования, 2016.

https://cyberleninka.ru/article/n/konets-sistemy-obyazatelnogo-obrazovaniya

[8] K. Gusev, "XXIV съезд КПСС и отечественная историография" in 1971 Издательство Академии наук СССР, 1971.

https://bit.ly/2uCNSxQ 